REVIEW

\title{
The effect of asthma and its treatment on growth
}

\section{J M Doull}

Arch Dis Child 2004;89:60-63. doi: 10.1136/adc.2003.014365

Asthma has little, if any, significant effect on attained adult height. Untreated asthma results in a delay of puberty by approximately 1.3 years, and pubertal delay is likely to explain the majority of apparent growth failure in asthmatics. All currently available inhaled corticosteroids (ICS) result in growth suppression at conventional doses (400 $\mu \mathrm{g} /$ day of beclomethasone dipropionate equivalent), but the growth suppressive effects are relatively short lived, after which growth reverts to pretreatment levels. Younger, prepubertal children, appear more sensitive to the growth suppressive effects of ICS. Asthmatic children receiving conventional doses of ICS (400 $\mu \mathrm{g} /$ day of BDP equivalent) will attain an adult height indistinguishable from their predicted adult height (based on their mid parental height), and no different from non-asthmatics. Adult height could possibly be decreased in severe asthmatics, but this is unlikely to be greater than a $1.2 \mathrm{~cm}$ decrement. Recent longitudinal studies offer reassurance that at conventional doses ICS do not have significant long term effects on growth, and that their benefits consistently outweigh their side effects.

Correspondence to: Dr I J M Doull, Cystic Fibrosis/Respiratory Unit, Department of Child Health, University Hospital of Wales, Cardiff CF14 4XW, UK; doullij@cf.ac.uk

Accepted 7 June 2003
$\mathrm{T}$ here is understandable parental concern over the side effects of prescribed medicines in children. For the parents of an asthmatic child, casually mentioning that you intend starting their child on a corticosteroid, even in the inhaled form, conjures up terrifying visions of stunted growth, obesity, and disgraced Olympic 100 metre champions. These concerns have been fuelled by reports of significant short and medium term growth suppression in association with inhaled corticosteroids (ICS). ${ }^{1-4}$ However, two recent studies have clarified many of the uncertainties over the longer term effects of ICS, ${ }^{56}$ and so from a medical perspective the perceived risk of ICS on growth has swung over the past 25 years from nil, to significant, to a more measured negligible in the majority of cases.

Historically it was believed that asthmatics may be shorter than average. In the mid nineteenth century Henry Hyde Salter, a physician at Guy's Hospital in London, observed, "If the asthma has come on young, he is generally below the average height. Some asthmatics, however ... have nothing whatever the matter with their appearance and would be taken for perfectly healthy people." The first concerns that the treatment of asthma might affect children's height arose in the 1960s. Alexander Spock compared the height centiles of children attending his asthma clinic in North Carolina over a 20 year period with a group of normal children without asthma, and could determine no difference between the distribution of height centiles of the two groups. ${ }^{7}$ However, when he compared a group of asthmatic children from Colorado, where it was common to use cortisone injections in the treatment of asthma, he observed that the Denver children's height centiles were much lower than either his asthmatic or normal control children in North Carolina. He concluded that asthma had little effect on growth in children, but that its treatment might impair growth.

\section{THE EFFECT OF ASTHMA ON PUBERTY, GROWTH, AND ATTAINED ADULT HEIGHT}

The vast majority of asthmatic children will attain a normal adult height, and most perceived growth failure is due to pubertal delay. In a mixed cross sectional longitudinal cohort study of 531 boys aged between 2 and 20 years of age attending a Belgian residential asthma institute, Hauspie and colleagues noted that, compared to both British and Dutch reference values, boys with asthma were significantly older in attaining each Tanner pubic hair stage. ${ }^{8}$ As a result peak height velocity in the asthmatic boys was delayed by approximately 1.3 years, giving the impression of reduced stature in the asthmatic boys during adolescence, but that growth continued to an older age.

This effect on puberty was reflected in the Melbourne prospective longitudinal asthma study. ${ }^{9}$ Children labelled as asthmatic were graded by severity and compared with normal controls. Those with the most severe asthma were significantly shorter at age 14 years, but by 21 years of age their height was no different to mild or moderate asthmatics, or normal controls. Similarly Balfour-Lynn ${ }^{10}$ described the growth of a group of asthmatic children as they proceeded through puberty, the majority of who were treated prior to the widespread introduction of ICS. Growth followed a height centile until approximately 10 years of age, but subsequently half the children showed pubertal delay with decreased growth, and height only returned to the baseline centile once puberty had commenced. The mean attained adult height did

Abbreviations: BDP, beclomethasone dipropionate; BUD, budesonide; FP, fluticasone propionate; ICS, inhaled corticosteroids 
not differ significantly from predicted height derived from mid-parental height.

The most comprehensive data to date, provided by countries with military conscription, suggests that adult height in asthmatics is close to normal. A study of 9231017 year old Israeli military conscripts reported no significant difference in height between severe asthmatics and nonasthmatic controls, ${ }^{11}$ and indeed mild asthmatic males were slightly taller than non-asthmatic controls. A more recent report on the height of 173034 18-year old Swedish military conscripts (including 8531 asthmatics) showed a small but significant difference in height between asthmatics and normal controls, with a negative correlation between height and asthma severity. ${ }^{12}$ The authors were able to analyse four different cohorts between 1983 and 1996, and reassuringly, despite a 40-fold increase in the use of inhaled corticosteroids in Sweden over that time period, the difference in height between asthmatics and controls decreased with each successive age cohort, with the greatest convergence in values observed in severe asthmatics. In the 1996 cohort mean height was $0.7 \mathrm{~cm}$ less in the asthmatic conscripts, with the maximum difference being $1.2 \mathrm{~cm}$ between the severe asthmatics and non-asthmatics. As many of the subjects in both these studies had not reached their ultimate adult height, it is likely that the observed differences between asthmatics and normal controls are an overestimate.

\section{THE EFFECT OF TREATMENT OF ASTHMA ON GROWTH}

Regular systemic corticosteroids such as oral prednisolone result in a dose dependent impairment of growth. ${ }^{13}$ Hence the advent of inhaled corticosteroids in the early 1970s revolutionised asthma care in children. Early reports concentrated on their therapeutic efficacy, while their side effects appeared negligible compared to oral corticosteroids. ${ }^{14-16}$ The first suggestion that inhaled corticosteroids might have a adverse effect on growth was a report in $1988^{17}$ of a significant negative inflection in the height standard deviation score (SDS) at the onset of commencing regular beclamethasone dipropionate (BDP). Over the following 25 years all of the currently available ICS have been shown to cause a dose dependent growth suppression. When reviewing the effect of ICS on growth, it is useful to divide the reports into short term studies (less than six months), medium term studies (6-24 months), and longer term studies (more than 24 months and up to adulthood).

\section{Short term studies}

Short term studies have utilised knemometry, an extremely accurate means of measuring lower leg length growth, which allows crossover studies to be performed rapidly. For example, Wolthers and Pedersen showed that both 2.5 and $5 \mathrm{mg}$ of oral prednisolone daily completely interrupted knenometrically measured lower leg growth in mildly asthmatic children. ${ }^{18}$ Inhaled corticosteroids do not have such a pronounced effect; the same authors showed no significant effect on lower leg growth for either 200 or $400 \mu \mathrm{g} /$ day of budesonide (BUD) for two weeks, but a significant $66 \%$ decrease in growth while receiving budesonide $800 \mu \mathrm{g} /$ day. ${ }^{19}$ A number of investigators have reported that BUD has no significant effect on short term growth at a dose of $200 \mu \mathrm{g} /$ day, ${ }^{19-21}$ causes significant growth impairment at $800 \mu \mathrm{g} /$ day, ${ }^{19}{ }^{20}$ but results at a dose of $400 \mu \mathrm{g} /$ day are inconsistent. ${ }^{19-21}$ In contrast BDP has no effect at a dose of $200 \mu \mathrm{g} /$ day, but consistently results in decreased short term growth at a dose of either 400 or $800 \mu \mathrm{g} /$ day. ${ }^{22}{ }^{23}$ Fluticasone propionate (FP) has no effect on growth at a dose of $200 \mu \mathrm{g}$ / day. ${ }^{21} 24$
There are however major difficulties over the interpretation of knenometric studies due to the marked intra-subject and inter-subject variability in short term lower leg growth. Even within the same laboratory there are substantial variations between studies in reported lower leg growth while receiving placebo. Furthermore as the growth suppressive effects of ICS are probably short lived (see below), there will be marked differences of effect between subjects who are receiving ICS at onset of the study and those that are not. Thus short term lower leg growth is a very poor correlate of statural growth, ${ }^{25}$ and the short term effects of any given treatment cannot be extrapolated to the longer term.

\section{Medium term studies}

Medium term studies address growth between 6 and 24 months of follow up. Early reports on the therapeutic effects of ICS were not designed to detect small effects on growth, ${ }^{14-16}$ but in the past 10 years there have been six well designed randomised double blind studies where medium term growth has been addressed: four for BDP (one versus theophylline, ${ }^{1}$ one versus placebo, ${ }^{2}$ one versus salmeterol, ${ }^{3}$ and one versus placebo and theophylline ${ }^{4}$ ); and two studies comparing FP with either placebo $^{26}$ or $\mathrm{BDP}^{27}$ All four controlled studies for BDP reported significant growth suppression at a dose of $400 \mu \mathrm{g} / \mathrm{day}$, and a recent metaanalysis of these four studies calculated that BDP at this dose results in a decrease in linear growth of $1.51 \mathrm{~cm} /$ year $(95 \% \mathrm{CI}$ 1.15 to 1.87$).^{28}$ Growth in children receiving $200 \mu \mathrm{g} /$ day of BDP appears unaffected. Younger, prepubertal children, appear more sensitive to the growth suppressive effects of ICS. $^{36}$

A randomised, double blind multicentre study ${ }^{26}$ compared FP $100 \mu \mathrm{g} /$ day or $200 \mu \mathrm{g}$ /day with placebo via diskhaler in a group of 325 prepubescent children over one year. Mean height increased over 12 months by $6.15 \mathrm{~cm}$ in the placebo treated group, $5.94 \mathrm{~cm}$ in those receiving $100 \mu \mathrm{g} /$ day, and by $5.73 \mathrm{~cm}$ in those receiving $200 \mu \mathrm{g} /$ day $(\mathrm{p}=0.3$ overall). However, a reanalysis of this data established a significant decrease in growth of $0.43 \mathrm{~cm} /$ year (95\% CI 0.01 to 0.85 ) in those receiving $200 \mu \mathrm{g} /$ day of FP compared to placebo, while growth in those receiving $100 \mu \mathrm{g} /$ day was not significantly different to placebo. ${ }^{28}$ In the only comparison of BDP and FP, Rao and colleagues ${ }^{27}$ compared FP $200 \mu$ g/day with BDP $400 \mu \mathrm{g} /$ day via metered dose inhaler in a randomised, double blind single centre study in 23 prepubescent children over 20 months. Growth was significantly decreased in those receiving $\mathrm{BDP}$ compared to $\mathrm{FP}(4.94 \mathrm{~cm} /$ year compared to $5.75 \mathrm{~cm} /$ year; $95 \%$ CI 0.45 to 1.16 ).

A major difficulty with short and medium term studies is that the magnitude of reported growth suppression flies in the face of clinical observations. For example, if the pooled effect of BDP at the conventional dose of $400 \mu \mathrm{g} /$ day were consistent over a 10 year period, growth decrement would be a not inconsiderable $15 \mathrm{~cm}$. Extrapolation of the of the short term effect of BUD $800 \mu \mathrm{g} /$ day gives even more inconceivable results. Medium term studies give conflicting results on the duration of the effect, with some authors reporting that the effect is short lived, ${ }^{42}$ while others report that the effect persists for the duration of the study. ${ }^{13}$

\section{Longer term studies}

Longer term studies assess growth for more than 24 months and up to adulthood. There is a single randomised controlled study, ${ }^{5}$ and four longitudinal observational studies. ${ }^{6} 103031$ The landmark Childhood Asthma Management Program Research Group (CAMP) is unique in its 4-6 year period of follow up, showing that the effects of ICS on growth are relatively short lived. It was designed to measure the effects of regular inhaled anti-inflammatory agents on lung growth, with the primary end point being the change in forced 
expiratory volume in 1 second $\left(\mathrm{FEV}_{1}\right) .{ }^{9}$ In a double blind design, 1041 mild to moderate asthmatic children aged 5-12 years were randomised to regular BUD $200 \mu \mathrm{g}$ twice daily, nedocromil $8 \mathrm{mg}$ twice daily or placebo and followed for 4-6 years. Although both BUD and nedocromil improved control of asthma, with BUD offering greater control than nedocromil, neither BUD nor nedocromil had any significant effects

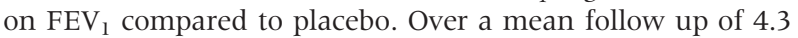
years, the children randomised to receive BUD grew $1.1 \mathrm{~cm}$ less than those who received placebo $(22.7 \mathrm{~cm}$ versus $23.8 \mathrm{~cm}, \mathrm{p}=0.005)$. The difference in growth between those receiving BUD and placebo was confined almost entirely to the first year, and growth in the two groups appeared very similar thereafter. There was no significant difference in growth between those who received nedocromil and placebo. Over the course of the study there were no significant differences in change in bone density or bone age between the three groups.

There are no randomised controlled studies of asthma medication into adulthood, and three small retrospective studies have given slightly contradictory results. Both Balfour-Lynn ${ }^{10}$ and Silverstein and colleagues ${ }^{30}$ reported no differences in attained adult height between asthmatics that received ICS in childhood and non-asthmatics. In contrast Van Bever and colleagues ${ }^{31}$ reported that although there were no significant differences in attained adult height between adult asthmatics who had or had not received ICS in childhood, those who received ICS had significantly lower adult height compared to their predicted adult height based on mid parental height.

The most comprehensive data were reported by Agertoft and Pedersen, ${ }^{6}$ who fastidiously recorded the growth of a cohort of over 300 asthmatic children over a 14 year period. In 1986, based on national guidelines, they had elected to change all of their patients with asthma onto regular ICS; virtually all received BUD. A small number of parents were unwilling for their children to commence ICS, and so this group of children and the subject's healthy siblings acted as controls. The study was not controlled, and the number of asthmatic controls decreased over the years, mostly through commencing ICS. The predicted adult height was calculated on the mid parental height, with adjustment for the subject's sex.

Growth decreased significantly after commencing BUD, from a mean of $6.1 \mathrm{~cm} /$ year (95\% CI 5.7 to 6.5) prior to commencing, to $5.1 \mathrm{~cm} /$ year in the first year (95\% CI 4.7 to $5.5, \mathrm{p}<0.001$ ), and $5.2 \mathrm{~cm} /$ year in the second year $(95 \%$ CI 5.1 to $5.9, \mathrm{p}=0.02$ ). Subsequent growth was no different to controls. Over the mean of 9.2 years it took to reach adult height, the subjects in the BUD group received a mean daily dose of $412 \mu \mathrm{g} /$ day of BUD (range 100-877 $\mu \mathrm{g} / \mathrm{day}$ ). Compared to their predicted adult height, there was no significant difference in attained adult height between those who received BUD $(+0.3 \mathrm{~cm} ; 95 \% \mathrm{CI}-0.6$ to 1.2$)$, asthmatic controls $(-0.2 \mathrm{~cm} ; 95 \% \mathrm{CI}-2.4$ to 2.1$)$, or the sibling controls $(+0.9 \mathrm{~cm} ; 95 \% \mathrm{CI}-0.4$ to 2.2$)$. There was no relation between the initial reduction in growth after commencing therapy and the difference between predicted and attained adult height, suggesting that the initial growth suppression was transient and had little long consequence.

\section{A PRAGMATIC APPROACH}

What therefore is a sensible approach to inhaled corticosteroids in childhood? The recent British guideline on the management of asthma advocates starting inhaled corticosteroids at a dose appropriate to the disease severity. ${ }^{32}$ For the vast majority of children this will be at a BDP equivalent dose of $200 \mu \mathrm{g} /$ day, where side effects are extremely unlikely. All children receiving $400 \mu \mathrm{g} / \mathrm{day}$ or more should have their height measured every six months, preferably by the same person using the same equipment. A small short term decrement in height velocity is possible, but more striking and prolonged decreases in height velocity are of greater concern. Recent reports have highlighted significant and often symptomatic adrenal suppression in children receiving high doses of inhaled corticosteroids, ${ }^{33-35}$ particularly fluticasone propionate. Many of the children had associated growth suppression preceding the demonstration of adrenal suppression. ${ }^{33-35}$ Although the majority of cases were receiving doses of inhaled corticosteroid well above the licensed recommendations, some appeared to be receiving more conventional doses. Thus it is prudent to recommend that any child who requires more than $400 \mu \mathrm{g} /$ day BDP equivalent a day to control their asthma should have the diagnosis and treatment reassessed, ${ }^{32}$ and that any child receiving inhaled corticosteroids with striking or prolonged decrease in height velocity should have an urgent assessment of adrenal function.

Competing interests: The author has received financial support to attend meetings and given advice to Astra-Zeneca, Glaxo-Smith-Kline, Merck Sharpe and Dohme, and Schering-Plough

\section{REFERENCES}

1 Tinkelman DG, Reed CE, Nelson HS, et al. Aerosol beclomethasone dipropionate compared with theophylline as primary treatment of chronic, mild to moderately severe asthma in children. Pediatrics 1993:92:64-77.

2 Doull IJM, Freezer NJ, Holgate ST. Growth of prepubertal children with mild asthma treated with inhaled beclomethasone dipropionate. Am J Respir Crit Care Med 1995;151:1715-19.

3 Verberne AA, Frost C, Roorda RJ, et al. One year treatment with salmeterol compared with beclomethasone in children with asthma. Am J Respir Crit Care Med 1997; 156:688-95.

4 Simons FER. Canadian Beclomethasone Dipropionate-Salmeterol Xinafoate Study Group. A comparison of beclomethasone, salmeterol and placebo in children with asthma. N Engl J Med 1997;337:1659-65.

5 The Childhood Asthma Management Program Research Group. Long term effects of budesonide or nedocromil in children with asthma. N Engl J Med 2000;343: 1054-63.

6 Agertoft L, Pedersen S. Effect of long term treatment with inhaled budesonide on adult height in children with asthma. N Engl J Med 2000;343:1064-9.

7 Spock A. Growth patterns in 200 children with bronchial asthma. Ann Allergy 1965;23:608-15.

8 Hauspie R, Susanne C, Alexander F. Maturational delay and temporal growth retardation in asthmatic boys. J Allerg Clin Immunol 1977:59:200-6.

9 Martin AJ, Landau LI, Phelan PD. The effect of growth on childhood asthma. Acta Paedr Scand 1981;70:683-8.

10 Balfour-Lynn L. Growth and childhood asthma. Arch Dis Child 1986:61:1049-55.

11 Shohat M, Shohat T, Kedem R, et al. Childhood asthma and growth outcome. Arch Dis Child 1987;62:63-5.

12 Norjavaara E, Gerhardsson D, Verdier M, et al. Reduced height in Swedish men with asthma at the age of conscription for military service. J Pediatr 2000; 137:25-9.

13 Kerrebijn KF, De Kroon JPM. Effect on height of corticosteroid therapy in asthmatic children. Arch Dis Child 1968;43:556-61.

14 Godfrey S, König P. Treatment of childhood asthma for 13 months and longer with beclomethasone dipropionate aerosol. Arch Dis Child 1974:49:591-6.

15 Francis RS. Long term beclomethasone dipropionate aerosol therapy in juvenile asthma. Thorax 1976;31:309-14.

16 Graff-Lonnevig V, Kraepelien S. Long term treatment with beclomethasone dipropionate aerosol in asthmatic children with special reference to growth. Allergy 1979;34:57-61

17 Littlewood JM, Johnson AW, Edwards PA, et al. Growth retardation in asthmatic children treated with inhaled beclomethasone dipropionate. Lancet 1988;i:116-17.

18 Wolthers OD, Pedersen S. Short term linear growth in asthmatic children during treatment with prednisolone. BMJ 1990;301:145-8.

19 Wolthers O, Pedersen S. Controlled study of linear growth in asthmatic children during treatment with inhaled glucocorticosteroids. Pediatrics 1992;89:839-42.

20 Wolthers $\mathrm{O}$, Pedersen S. Growth of asthmatic children during treatment with budesonide: a double blind trial. BMJ 1991;303:163-5.

21 Agertoft L, Pedersen S. Short term knemometry and urine cortisol excretion in children treated with fluticasone propionate and budesonide: a dose response study. Eur Respir J 1997;10:1507-12.

22 MacKenzie CA, Wales JK. Growth of asthmatic children. BMJ 1991;303:416.

23 Wolthers O, Pedersen S. Short term growth during treatment with inhaled fluticasone propionate and beclomethasone dipropionate. Arch Dis Child 1993:68:673-6.

24 Visser MJ, van Aalderen WM, Elliott BM, et al. Short term growth in asthmatic children using fluticasone propionate. Chest 1998;113:584-6.

25 Hermanussen M, Burmeister J. Standards for the predictive accuracy of short term body height and lower leg length measurement on half annual growth rates. Arch Dis Child 1989;64:259-63. 
26 Allen DB, Bronsky EA, LaForce CF, et al. Growth in asthmatic children treated with fluticasone propionate. J Pediatr 1998;132:472-7.

27 Rao R, Gregson RK, Jones AC, et al. Systemic effects of inhaled corticosteroids on growth and bone turnover in childhood asthma: a comparison of fluticasone and beclomethasone. Eur Respir J 1990:13:87-94.

28 Sharek PJ, Bergman DA. The effect of inhaled steroids on the linear growth of children with asthma: a meta-analysis. Pediatrics 2000; 106(E8):20342668

29 Doull IJM, Campbell MJ, Holgate ST. Duration of growth suppressive effects of regular inhaled corticosteroids. Arch Dis Child 1997;78:172-3.

30 Silverstein MD, Yunginger JW, Reed CE, et al. Attained adult height after childhood asthma: effect of glucocorticoid therapy. J Allergy Clin Immunol 1997:99:466-74.
31 Van Bever HP, Desager KN, Lijssens N, et al. Does treatment of asthmatic children with inhaled corticosteroids affect their adult height? Pediatr Pulmonol 1999;27:369-75.

32 SIGN/BTS. British guideline on the management of asthma. Thorax 2003:58(suppl 1): 1-94.

33 Patel L, Wales JK, Kibirige MS, et al. Symptomatic adrenal insufficiency during inhaled corticosteroid treatment. Arch Dis Child 2001;85:330-4.

34 Wong JY, Zacharin MR, Hocking N, et al. Growth and adrenal suppression in asthmatic children on moderate to high doses of fluticasone propionate. J Paediatr Child Health 2002:38:59-62.

35 Drake AJ, Howells RJ, Shield JPH, et al. Symptomatic adrenal insufficiency presenting with hypoglycaemia in children with asthma receiving high dose inhaled fluticasone propionate. BMJ 2002;324:1081-3.

\section{IMAGES IN PAEDIATRICS}

\section{Pacemaker twiddling}

A 10 year old boy with severe learning disabilities had a permanent subpectoral endocardial pacemaker for intermittent heart block. Twenty three months later, he presented with an episode of collapse associated with pacemaker failure. Chest $x$ ray examination showed that he had twiddled the pacemaker clockwise and pulled the lead out of the right ventricle (radiograph A). A new pacing system was inserted (radiograph B). At revision, surprisingly, there was no fibrosis around the generator or wire. In an attempt to fix the generator more firmly, it was placed in the original subpectoral pocket, but in a dacron pouch (Parsonnet pouch) to promote fibrosis. He presented again, 17 days later, with a further episode of collapse associated with pacemaker failure. Repeat chest $x$ ray examination showed that he had twiddled the pacemaker anticlockwise and the pacing lead had perforated the right ventricle into the abdomen (radiograph $\mathrm{C}$ ). This illustrates the difficulties and the potential risk in children with learning disabilities.

Twiddler's syndrome leading to pacemaker failure, although rare, is recognised in children. Children with learning disabilities are more susceptible because of conscious or subconscious twisting of the pacemaker box and poor comprehension of consequences. Subpectoral implantation of the pacing box may prevent this complication, although this was unsuccessful in this child. A chest radiograph should be performed in cases of pacemaker dysfunction to exclude this complication.

S J Murugan, M E C Blackburn Leeds General Infirmary, UK; jothidevi1@ hotmail.com
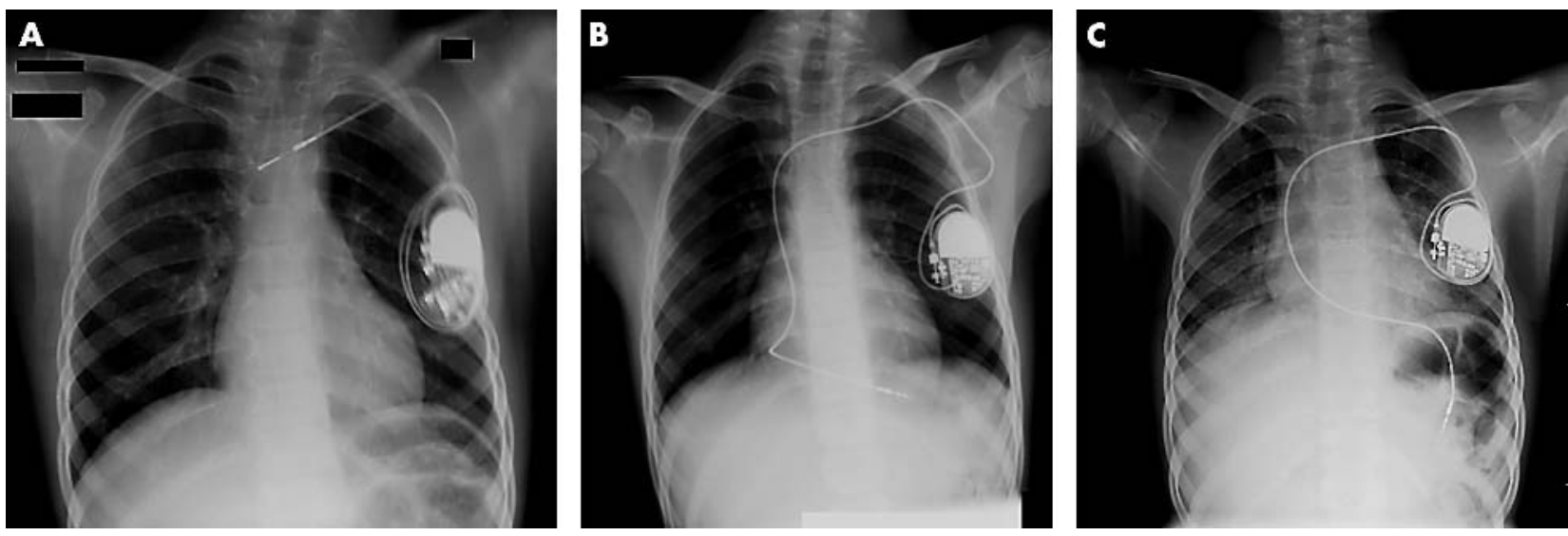